\title{
The Worldwide Environmental Encroachments of COVID-19 Outbreak
}

\author{
Mohd Kafeel Ahmad Ansari ${ }^{1 *}$, Nasreen Islam Khan², Abdullah Adil \\ Ansari $^{1}$ and Gary Owens ${ }^{2}$ \\ ${ }^{1}$ Department of Biology, Faculty of Natural Science, University of Guyana, South America \\ ${ }^{2}$ Environmental Contaminants Group, Future Industries Institute, University of South \\ Australia, Mawson Lakes, Australia \\ *Corresponding Author: Mohd Kafeel Ahmad Ansari, Department of Biology, Faculty \\ of Natural Science, University of Guyana, South America.
}

Received: March 22, 2021

Published: April 27, 2021

(C) All rights are reserved by Mohd Kafeel

Ahmad Ansari., et al.

\begin{abstract}
Following the global COVID-19 outbreak while many articles have been published on the medical issues associated with the outbreak, the environmental impacts of COVID-19 have not been widely studied. Researchers are divided on whether COVID-19 will shrink environmental contamination or lead to significant future environmental damage. This study therefore examined the environmental impacts of COVID-19 on climate change, water pollution and sustainable environment use. The article is divided into four sections. In the first section the current literature related to COVID-19 is reviewed. In the second section a recent update on urban water pollution due to COVID-19 is presented, followed by a discussion of the impact of COVID-19 on climate change and environmental sustainability in the third section. Finally, in the fourth section the global environmental impact of COVID-19 is discussed. The findings of this study reveal that the short term lockdown of industries has had some positive environmental impacts worldwide, such as minimisation of large scale air pollution and also decreased pollution of many local water bodies including ecumenical beaches, Chinchwad, Ganga, Pimpri, Yamuna rivers in India, and canals of Venice, Italy.
\end{abstract}

Keywords: Climate Change; COVID-19 Outbreak; Environmental Impact; Lockdown; Pandemic; Sustainability

\section{Introduction}

The COVID-19 outbreak, which appeared first in Wuhan, China in December 2019, rapidly spread worldwide, including Asia, Europe and the United States, within just a few months [1], resulting in the World Health Organization (WHO) declaring a global health emergency in January 2020 [2-4]. Provisionally named 2019-novel coronavirus (2019-nCoV) and scientifically denoted as the severe acute respiratory syndrome-corona virus 2 (SARS-CoV-2), it was subsequently colloquially recognized as COVID-19 [5,6]. As a zoonotic coronavirus it is known to cross species to infect human populations, with subsequent highly efficient human-to-human virus transmission. SARS-CoV-2 has already spread to more than 200 countries worldwide [7].

Four weeks after China announced its first COVID-19 case; the first Indian case was on $30^{\text {th }}$ January 2020 in Kerela. To combat the pandemic India took immediate action leading for the first time to national restrictions on travel and work. A sudden jump in Indian
COVID-19 cases occurred on March $4^{\text {th }}[47]$ (https://www.mohfw. gov.in/), and subsequently in response the first international travel advisory restrictions to China, Iran, Italy, Japan and the Republic of South Korea was issued on March $11^{\text {th }}$. In addition, significant passenger testing at key entry points across India, especially airports, was initiated and since March $16^{\text {th }}$ mass gatherings ceased nationwide [8]. The unprecedented first nationwide lockdown occurred for fourteen hours on March 22 ${ }^{\text {nd }}$, followed by a 21-day lockdown from March $24^{\text {th }}$. During this lockdown restrictions and self-quarantine measures were strictly enforced to specifically reduce contamination in several high-risk industries. It is envisioned that such severe lockdowns could potentially have dramatic effects on environmental pollution. For example, with many polluting industries closed, the changes in water pollution occurring during lockdown can provide an insight into the feasibility of achieving of high water quality. Likewise, such lockdowns may lead to reductions in both environmental greenhouse gas emissions and air pollution [9]. 
Globally, by 09 October 2020 with more than 36,361,054 confirmed COVID-19 cases and associated deaths approaching $1,056,186$, governments worldwide responded by imposing harsh containment and quarantine rules $[1,10]$. The worldwide distribution of COVID-19 cases and deaths, as of 09 October 2020, is shown in figure $1 \mathrm{a}$ and $1 \mathrm{~b}$. Therefore, worldwide significant effort has been directed to finding efficient approaches to control rapid transmission of COVID-19 to avoid human-to-human spread. Previous studies have suggested that several climate factors, including humidity and temperature, may play important roles in the development and spread of the 2003 SARS infection [11]. While COVID-19 initially spread in low temperature areas of China, with subsequent major outbreaks in Iran, Japan, Northern Italy and South Korea, where these new virus epicentres had similar temperature and latitude, i.e. were all along the $30-50^{\circ} \mathrm{N}$ " zone, the outbreak of disease subsequently extended to higher temperature regions like India, the Middle East and Thailand, due to international travel [12].

Therefore, to avert the spread of COVID-19, most countries have adopted social distancing strategies and have advised people to safely stay at home throughout an extended period of strict global lockdown. Worldwide, the city streets are forsaken; the usually bustling bars, pubs and theatres are closed; operation of public transport has declined and most governments have released advisories to their citizens to work remotely from their homes. In India, since $24^{\text {th }}$ March 2020 to the third week of April 2020 a four-week nationwide lockdown crippled large geographic areas of the country, with similar impacts on economies of other governments and the environment across the globe [7]. However some positive impacts of a four-week lockdown were observed. For example, the atmospheric level of particulate matter (PM 2.5) and $\mathrm{NO}_{2}$ concentrations significantly decreased (Figure 2). Thus, the main objective of this article was to highlight the potential environmental impacts of COVID-19 and the induced effects of imposed lockdowns on environment sustainability and the potential to clean our natural resources (i.e. air and water).

In India following the first reported COVID-19 cases in late January 2020, the Prime Minister declared a state of emergency on the evening of $24^{\text {th }}$ March 2020 and a countrywide lockdown was implemented on $25^{\text {th }}$ March 2020. As a direct result all industries and tourism activities were completely closed from $25^{\text {th }}$ March 2020 , and the pollution associated with such sources was consequentially almost completely halted, which resulted in a unique
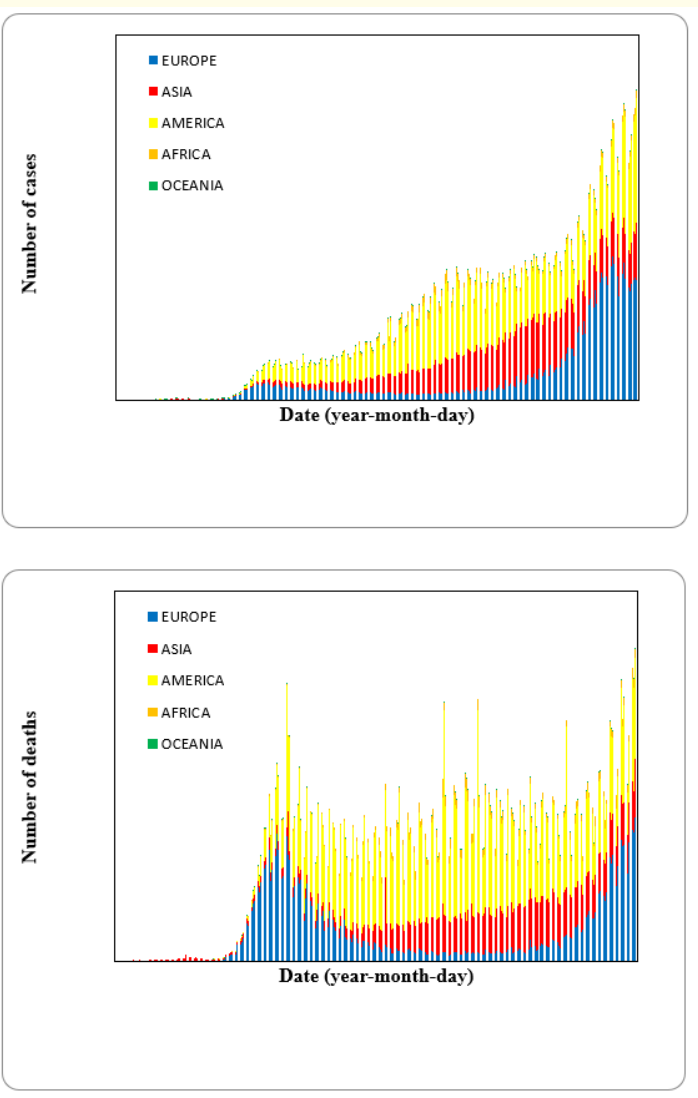

Figure 1: Worldwide distribution of COVID-19 cases (A) and deaths (B) as of 09 October 2020 (https://ourworldindata.org/ coronavirus-testing) [46].
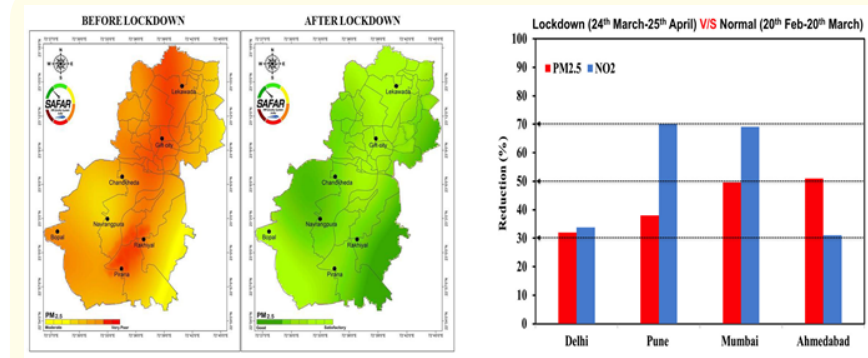

Figure 2: Comparison of PM 2.5 levels in Ahmedabd before lockdown (24th March-25th April 2020) and after lockdown (24th March-25thApril, 2020) [Updated: 7th May 2020] [41]. The reddish pale yellow colour shows elevated PM 2.5 level before nationwide lockdown whereas the green colour shows the reduction in PM 2.5 levels after lockdown). On the right hand side the bar graph compares the reduction in PM 2.5 (red bars) and NO2 levels (blue bars), for four Indian cities for the same period (http://safar.tropmet.res.in/). 
opportunity to study the effect of the lockdown on the water quality of various rivers like the Chinchwad, Ganga, Pimpri and Yamuna without continued effluxes of pollution.

\section{Global encroachments of COVID-19 on water pollution}

Urban impact of lockdown on water bodies

Unplanned industrialization, overexploitation of resources and urbanization have routinely led to detrimental effects on aquatic environments. Therefore, the COVID-19 induced lockdown provides a unique opportunity to study the status of various pollutions including water contamination without continued pollutant efflux and to measure how reductions in pollution can affect water quality. One direct result of the lockdowns was that during these periods the major industrial sources of pollution that routinely affects aquatic ecosystems (i.e. crude oil, heavy metals, industrial wastewater disposal, and plastics [13], were either significantly decreased or stopped completely. Therefore, logically, while lockdown could lead directly to reduce levels of water pollution, how quickly this would occur was not clear. However these reductions were quite rapid. For example, in Italy where COVID-19 had crippled the nation, shortly after the lockdown was implemented, news media reported Venice's Grand Canal became significantly clearer, and that many long forgotten aquatic species reappeared [14]. Likewise, many beaches worldwide including Acapulco (Mexico), Barcelona (Spain) and Salinas (Ecuador-South America) were observed to have cleaner water [15]. In the Indian context, significant changes also occurred due to lockdown, where during this time, pollution levels continually declined. For example, the sacred Ganges, an incredibly polluted Indian river, became visually cleaner in many locations along its length during the nationwide lockdown period $[16,17]$. Moreover, the water quality of the tributaries of the Ganga, such as Hindon and Yamuna, also improved significantly [18]. The quality of water in the holy Ganga river significantly improved, by up to $40-50 \%$, since the national 21-day lockdown was announced on March 24, 2020 [17,19]. The central pollution control board, New Delhi also now described the quality of the Ganges river, just because of short term lockdown, as fit for fisheries and wildlife along with human bathing [20]. In many cities of West UP, for example, Aligarh, Baghpat, Bijnor, Bulandshahr, Meerut and Muzaffarnagar, industrial waste was commonly dumped in small rivers, where it is well known that one-tenth of the pollution of these rivers comes from unplanned industries. However, a national wide short term lockdown was helpful in reducing water pollution of these rivers [17].

\section{Lockdown made Ganga water potable}

According to a news report published in the Times of India, the corona epidemic has had a constructive impact on the Ganga river which is now cleaner than ever before. Factories polluting the Ganges are completely closed owing to the lockdown and simultaneously the ghats (valleys) along the Ganges are also bunged, therefore, the quality of the Ganges water has improved in Rishikesh and Haridwar, Uttrakhand so that after decades there is some hope that the water of the Ganges of the Har-Ki-Pauri could once again be potable [21]. Similarly, the Environment Conservation Association (ECA) conducted a study on the impact of the 21-day lockdown on river pollution that indicated positive results from three rivers including the Chinchwad, Indrayani, Mula and Pavana of Pimpri, part of the Metropolitan Region of Pune, Maharashtra state of India [21].

\section{Impact of lockdown on Yamuna river water}

A significant decline in the water pollution of the Yamuna river was also observed due to the shutdown of industry during the 21-day lockdown imposed in response to the COVID-19 pandemic [17]. According to a Delhi Jal Board report, the cessation of industry in Delhi-NCR during the lockdown led to an apparent increase in the water quality of the Yamuna river as tons of effluent and toxic wastes ceased to be discharged into the river. Today the Yamuna looks cleaner than it ever has before, indicating that cessation of efflux of industrial contaminants and industrial waste has definitely had a constructive effect on water quality [20]. Thus, the Yamuna is one of the countries rivers which has witnessed dramatic increases in water quality due to the national lockdown (Figure 3).

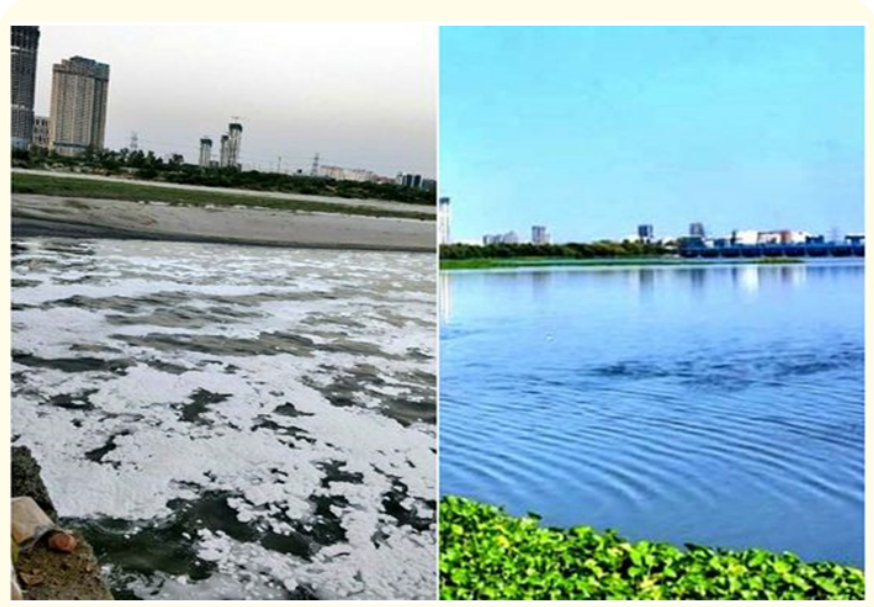

Figure 3: Visual impact of COVID-19 on the Yamuna water (Image Credit, Twitter@SudhaRamen IFS, Asia World, 05 April, 2020). 


\section{Climate change and environmental sustainability}

The comprehensive worldwide response to the COVID-19 pandemic has led to an unexpected decrease in both greenhouse gas emissions and air pollutants [23]. While the COVID-19 pandemic has had obvious and dramatic impacts on our personal work environments, the imposed lockdown has also provided important insights in to tackling the problem of air contamination worldwide [22].

Air pollution and greenhouse gas emissions both decreased across several continents [23] as individual countries ceased their industrial activities in an attempt to mitigate the spread of COVID-19. The imposed inactivity over large geographic areas also led to some unforeseen temperate changes due to decreased air pollution in some areas, including California, China, India and Italy $[24,25]$. This was not surprising, given that the transport sector was the primary source of many greenhouse gas emissions, where driving and aviation contributed approximately 72 and 11\% respectively, to total greenhouse gas emissions [26].

Since the unprecedented lockdown was first imposed by authorities on the streets of Wuhan, China; people have been isolated at home to maintain social distances [22]. Likewise, in Italy, the most panoptic travel restrictions since World War II were imposed. Similarly, in London, the usually busy bars, pubs, and theatres were closed and people advised to stay home for their safety. Globally flights have been cancelled, as the aviation industry buckles due to corona virus induced travel restrictions and border closures. Many countries have adopted social distancing and remote working strategies, designed to stop the spread of COVID-19, and hopefully reduce the rapid increase in the global death rate. All these sudden changes have also led to a few unforeseen positive consequences. The closure of businesses, industries and transport networks has resulted in a rapid drop in carbon emissions. For example, compared to the previous year, air pollution in New York was reduced by nearly $50 \%$ due to corona virus measures [22]. Likewise, China's Ministry of Ecology and Environment reported that compared to last quarter of 2019, in China alone, emissions had decreased by up to $25 \%$ at the beginning of 2020 as people were advised to stay home, factories were closed and Chinese coal use of China's six largest power plants decreased by $40 \%$ [27]. Amongst the 337 Chinese cities the fraction of good quality air also increased by $11.4 \%$ compared to the same time in 2019 . While satellite images of Europe, demonstrated that nitrogen dioxide $\left(\mathrm{NO}_{2}\right)$ emissions decreased over northern Italy, with similar decreases in Spain and the UK $[22,23]$.
While the current international corona virus pandemic has claimed tens of thousands of people's and shattered economies it may have also delivered positive environmental change as an unexpected positive effect. While atmospheric emission from industrial activity have plunged, it is uncertain how long such drops in emissions will persist, especially as countries roll back their selfimposed restrictions in attempt to restart their economies. When the pandemic ultimately subsides and lockdown ceases, will carbon and contaminant emissions "bounce back" to pre-pandemic levels so "that it will be as if this clear-skied interlude never happened? Or could the changes we see today have a more persistent effect?" [28].

It is well established that deforestation and increasing intensive farming land use can both significantly magnify the risk of zoonoses. Several reports have shown that $60 \%$ of subtropical and $45 \%$ of tropical forests have vanished worldwide due to anthropogenic activities [29]. This drastic decline in forest cover has been directly linked to an elevated risk of pandemics like COVID-19 [30]. For example, forest loss in West Africa led to wild mammals, including bats, coming in to greater contact with humans resulting in an Ebola outbreak. Several studies have indicated that "zoonotic spill over" is often associated with endangered species that are increasingly being specifically targeted by the hunting and wildlife trade [30]. This is a concern because such exotic species may carry novel pathogens which the human population has not been previously exposed to and thus could play havoc as a novel corona virus. The relative incidences of zoonotic spill over are increasing primarily driven by environmental degradation, as humans encroach on natural habitats and come into greater contact with exotic wildlife [30]. In addition, climate change, which alters rainfall/droughts patterns, change ocean $\mathrm{pH}$, increases temperatures and sea levels are also increasing the incidences of human exposure to zoonotic diseases. Even modest increases in global temperatures are anticipated to increase the risks of vector-borne diseases in new habitats. For instance, global temperature increases resulted in increased mosquito migration to warmer regions with consequential increased transmission of the dengue fever and Zika virus in these regions [29]. This clearly showed that global warming can indirectly result in new vector transfer of human pathogens to new previously unexposed regions and populations. It was also reported that in some countries prone to flooding, which occurs due to temperature rises, increases in the frequency of vector-borne diseases (e.g. dengue and malaria) by $14 \%$ and $30 \%$, respectively were also observed [30]. Thus, when considering the potential effects of global pandemics on improving environmental sustainability it is important to take a wholistic approach. 
Relationship between COVID-19 and global environmental impact

Environmentally, the COVID-19 outbreak may actually lead to constructive impacts related to the closure of polluting industries and transport being completely banned from roads during lockdown. Hypothetically the reduction in such activities should lead to improved global air quality [22]. Many countries worldwide, for example, Brazil, China, India and Turkey, all registered decreases in air pollution levels during the lockdown [31]. A dramatic reduction in the concentrations of carbon dioxide $\left(\mathrm{CO}_{2}\right)$, nitrogen dioxide $\left(\mathrm{NO}_{2}\right)$, and Particulate Matter having a diameter $<2.5 \mu \mathrm{m}$ (PM $2.5)$ was reported in the main Chinese cities [32,33] since the continent went into lockdown. A similar decrease in the PM 2.5 level was also reported during the lockdown period in India (Figure 2).

The few existing studies have revealed that air pollution (e.g., carbon dioxide and nitrogen dioxide emissions) have recently decreased in several regions of the globe [34]. For example, nitrogen dioxide levels, determined by the Copernicus Sentinel-5P satellite, decreased across both France and Italy (Figure 4) during the pandemic $[32,35]$. However, while a minimum 10 -day average is really required to obtain a good aerial image [36], overall atmospheric pollution was clearly observed to reduce during the COVID-19 outbreak [22,37], where less air pollution in a time of COVID19 was good news and was an indicator that COVID 19 was indirectly having an environmental impact [38].

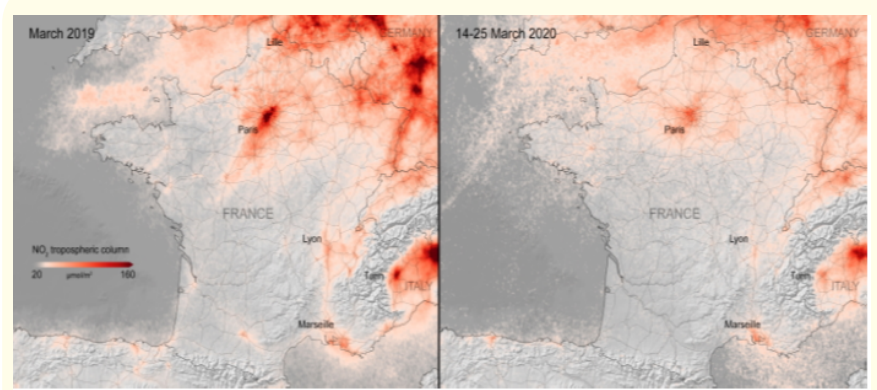

Figure 4: Images of France one year apart, pre- (March 2019) and post- (March 2020) COVID-19 demonstrating a decline in NO2 emissions (red shading) in major cities of France due to COVID-19 lockdowns, where darker shading indicates increased levels of $\mathrm{NO}_{2}$ (image credit: 32,38)
In India, initially the nationwide lockdown due to COVID-19 which was imposed for 3 weeks from March $24^{\text {th }}$ to $14^{\text {th }}$ of April, and thereafter extended to $3^{\text {rd }}$ May, 2020, led to almost all industrial activities and mass transportation being banned. Official data from the centre for pollution control board indicated that the pollution level in 88 cities countrywide drastically decreased only four days after initiation of the lockdown [31,39]. Therefore lockdown has been an efficient alternative measure to control air pollution and the present work explored the change in air quality during lockdown at a spatial scale in the megacity of Delhi [39]. Since COVID19 may be transported and remain viable on contaminant particles [40], reduction in air pollution could also potentially reduce SARS-CoV-2 spread. A recent report revealed that as a common atmospheric pollution particulate matter (PM) can be a highway for epidemic acceleration [40]. In India, air pollution had also significantly dropped 2 weeks into the COVID-19 lockdown. The air quality index (AQI; range 0-500) gives an overall appraisal of general air quality which is categorised as either good (0-50), satisfactory (51-100) or; poor (201-300). As of March 29, 2020 [41,42]; a total of 91 cities were classified as having 'Good' or 'Satisfactory' AQI, with 31 cities being classified as 'Good'; and no city considered to be in the 'Poor' AQI category (Figure 5). Additionally, the shutdown measures associated with COVID-19 have also led to a plummet in PM 2.5, decreasing by 15, 30 and 15\% in Ahmedabad, Delhi and Pune, respectively [43].

In New Delhi, cessation and/or diversion of flights resulted in a $71 \%$ plummet in air pollution within one week, where the level of PM 2.5 decreased from $91 \mu \mathrm{g} / \mathrm{m}^{3}$ (on 20 March 2020) to only 26 $\mu \mathrm{g} / \mathrm{m}^{3}$ a few days into the [44]. Similarly, the earlier, 'Janata Curfew', which was observed on March 22 (from 7 am-9 pm) also led to significant decreases in both particulate matter $\left(\mathrm{PM}_{10}\right)$ and nitrogen oxide (NOx) levels, with a $44 \%$ decline in $\mathrm{PM}_{10}$ observed mainly in Delhi between $22^{\text {nd }}$ and $23^{\text {rd }}$ of March 2020 [45].

\section{Conclusions and Prospects}

Environmental change is one most important global challenges of the $21^{\text {st }}$ century. Over the last decade, while much effort has been made to restore environmental ecosystems, little practical success on any significant scale has been made. However, during the last few months, the consequences of the COVID-19 pandemic have 


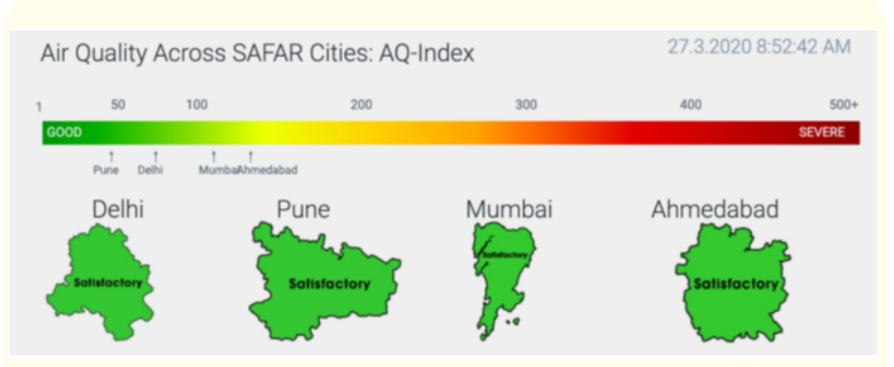

Figure 5: Image showing air quality across four major cities in India as of 27th March 2020 [41] (http://safar.tropmet.res.in/).

indirectly led to the successful recovery of many environmental ecosystems and simultaneous reductions in air and water pollution to a large extent that should definitely have a positive impact on climate change and maintaining environmental quality globally. Since, several reports have already shown that air and water pollution is increasing daily due to rapid and unplanned industries, which were closely correlated with severe chronic diseases in humans, the nationwide lockdown associated with the COVID-19 pandemic has provided a unique opportunity to improve the global environment. The outcome of the present study indicates that a short-term lock down of industries has some important environmental impacts, including decreased air and water pollution of many Indian national rivers including Chinchwad, Ganga, Pimpri and Yamuna. Moreover, the countrywide lockdown has efficiently not only in broken the chain of infections but has also had a rapid healing affect on natural ecosystems which augers well for maintaining environmental sustainability. Since COVID-19 is currently an active pandemic with no foreseeable end in sight, the constructive conclusions made here are based on limited data, which may be prone to high error. However, these conclusions do shed some light on of the current likely environmental impacts of COVID-19.

\section{Acknowledgments}

All authors would like to thank the Balkan Green Energy News, Central Pollution Control Board, Ministry of Environment, Forest and Climate Change, Government of India, Our Word Data, Indian Institute of Tropical Meteorology, Pune, SAFAR, Ministry of Earth Science, Government of India and all of the other media reports and figures cited.

\section{Funding}

This research has NOT received any kind of funding from any sources.

\section{Conflicts of Interest}

The authors declare no conflict of interest.

\section{Bibliography}

1. Renda A and Castro RJ. "Towards stronger EU governance of health threats after the COVID-19 pandemic". European Journal of Risk Regulation as part of the Cambridge Coronavirus Collection 11.2 (2020): 1-8.

2. Arora P., et al. "Learning from history: Coronavirus outbreaks in the past". Dermatologic Therapy 28 (2020): e13343.

3. Conforti C., et al. "COVID-19 and psoriasis: is it time to limit treatment with immunosuppressants? A call for action". Dermatologic Therapy 11 (2020): e13298.

4. Sohrabi C., et al. "World Health Organization declares global emergency: A review of the 2019 novel coronavirus (COVID-19)". International Journal of Surgery 76 (2020): 71-76.

5. Chen Y., et al. "SARS-CoV-2: virus dynamics and host response". The Lancet Infectious Diseases 20.5 (2020): 515-516.

6. El-Feky M and Bell DJ. “COVID-19”. Radiopaedia (2020).

7. Anjum NA. "Good in the Worst: COVID-19 Restrictions and Ease in Global Air Pollution". Preprint (2020).

8. Sharma S., et al. "Effect of restricted emissions during COVID-19 on air quality in India". Science of The Total Environment 728 (2020) 138878.

9. Liu W., et al. "Learning from the past: possible urgent prevention and treatment options for severe acute respiratory infections caused by 2019-nCoV". Chembiochem (2020).

10. WHO. "Coronavirus disease 2019 (COVID-19) Situation Report-75" (2020).

11. Bashir MF., et al. "Correlation between climate indicators and COVID-19 pandemic in New York, USA". Science of the Total Environment 728 (2020): 138835.

12. Kroumpouzos G., et al. "COVID-19: A Relationship to Climate and Environmental Conditions?". Dermatologic Therapy (2020). 
13. Häder DP., et al. "Anthropogenic pollution of aquatic ecosystems: emerging problems with global implications". Science of the Total Environment 713 (2020): 136586.

14. Clifford C. "The Water in Venice, Italy's Canals Is Running Clear amid the COVID-19 Lockdown - Take a Look" (2020).

15. Zambrano-Monserrate MA., et al. "Indirect effects of COVID-19 on the environment". Science of the Total Environment 728 (2020): 138813.

16. Mani KS. "The Lockdown Cleaned the Ganga More than 'NamamiGange' Ever Did" (2020).

17. Yunus AP., et al. "COVID-19 and surface water quality: Improved lake water quality during the lockdown". Science of the Total Environment 731 (2020): 139012.

18. Hindustan. "Lockdown reduce air pollution in India” (2020).

19. The Indian Express. "Message in the chorus: Stay with lockdown" (2020).

20. Times now. "Lockdown impact on water pollution in India" (2020).

21. The Times of India. "ECA studding impact of Covid-19 lockdown on rivers pollution in Pimpri” (2020).

22. Eroğlu H. "Effects of Covid-19 outbreak on environment and renewable energy sector". Environment, Development and Sustainability (2020).

23. Forster PM., et al. "Current and future global climate impacts resulting from COVID-19". Nature Climate Change 10 (2020): 913-919.

24. Calma J. "Maps show drastic drop in China's air pollution after coronavirus quarantine". The Verge (2020).

25. Herrero $\mathrm{M}$ and Thornton P. "What can COVID-19 teach us about responding to climate change?" Lancet Planet Health 4.5 (2020): e174.

26. IPCC, Intergovernmental Panel on Climate Change (IPCC 2018). "Summary for Policymakers". In: Global warming of $1.5^{\circ} \mathrm{C}$. An IPCC Special Report on the impacts of global warming of $1.5^{\circ} \mathrm{C}$ above pre-industrial levels and related global greenhouse gas emission pathways, in the context of strength- ening the global response to the threat of climate change, sustainable development, and efforts to eradicate poverty [V. Masson-Delmotte, P. Zhai, H. O. Pörtner, D. Roberts, J. Skea, P. R. Shukla, A. Pirani, W. Moufouma-Okia, C. Péan, R. Pidcock, S. Connors, J. B. R. Matthews, Y. Chen, X. Zhou, M. I. Gomis, E. Lonnoy, T. Maycock, M. Tignor, T. Waterfield (eds.)]. World Meteorological Organization, Geneva, Switzerland (2020): 32.

27. Myllyvirta L. "Coronavirus has temporarily reduced China's CO2 emissions by a quarter". Carbon Brief (2020).

28. BBC English. "Will Covid-19 have a lasting impact on the environment?" (2020).

29. Struchiner CJ., et al. "Increasing dengue incidence in Singapore over the past 40 years: population growth, climate and mobility". PLoS ONE 10.8 (2015): e0136286.

30. Arora NK and Mishra J. "COVID-19 and importance of environmental sustainability”. Environmental Sustainability 3 (2020): 117-119.

31. Sharma K. "Air pollution could make the COVID-19 pandemic worse for some people". The Verge (2020).

32. ESA. "Coronavirus lockdown leading to drop in pollution across Europe". European Space Agency (2020).

33. CAMS (2020).

34. McMahon J. "Study: coronavirus lockdown likely saved 77,000 lives in China just by reducing pollution". Forbes (2020).

35. Muhammad S., et al. "COVID-19 pandemic and environmental pollution: a blessing in disguise?" Science of the Total Environment 728 (2020): 138820.

36. Jonathan A. "Coronavirus: Lockdowns continue to suppress European pollution". BBC News (2020).

37. Watts J and Kommenda N. "Coronavirus pandemic leading to huge drop in air pollution". The Guardian (2020).

38. Balkan Green Energy News. "Air pollution sharply falls worldwide on COVID-19 lockdowns" (2020).

39. Mahato S., et al. "Effect of lockdown amid COVID-19 pandemic on air quality of the megacity Delhi, India". Science of the Total Environment 730 (2020): 139086. 
40. Euronews. "Covid-19 and climate: how much impact is the current lockdown really having on our environment?" (2020).

41. SAFAR - India. "System of Air Quality and Weather Forecasting And Research" (2020).

42. Vishnoi A. "Lockdown clears up India's air". Economics Times (2020).

43. The Hindu. "Air quality improves amid lockdown in India" (2020).

44. Davidson J. "Eco Watch, India's Air Pollution Plummets in COVID-19 Lockdown” (2020).

45. FP First Post. "India sees improved air quality during coronavirus lockdown, says CPCB". AQI improves to 'good' in 23 cities, 'satisfactory' in 65 (2020).

46. Our Word in Data (OWD). "Geographical distribution of COVID-19 cases" (2020).

47. MoEFC. "Ministry of Environment, Forest and Climate Change". In: SNk, Sundaray, DSR, Bharadwaj (Eds.), National Clean Air Programme New Delhi (2020).

\section{Assets from publication with us}

- Prompt Acknowledgement after receiving the article

- Thorough Double blinded peer review

- Rapid Publication

- Issue of Publication Certificate

- High visibility of your Published work

Website: https://www.actascientific.com/

Submit Article: https://www.actascientific.com/submission.php Email us: editor@actascientific.com

Contact us: +919182824667 